\title{
Analisis Manajemen Pemasaran Pada Aplikasi Shopee Dan Tokopedia
}

\author{
${ }^{1}$ Ayu Wulandari, ${ }^{2}$ Kafsul Anwar US \\ 1-2 Fakultas Ekonomi dan Bisnis Islam, UIN STS Jambi
}

\section{Article history}

Received: 12-03-2021

Revised: 01-04-2021

Accepted: 17-05-2021

*Corresponding Author:

Ayu Wulandari,

Fakultas Ekonomi dan

Bisnis Islam,

UIN STS Jambi

Email:

ayuwulndri234@gmail.co $\underline{\mathrm{m}}$

\begin{abstract}
Abstrak: Manajemen pemasaran pada setiap e-commerce sangat penting, tanpa adanya manajemen pemasaran yang baik sudah dapat dipastikan perusahaan tersebut akan hancur. Setiap e-commerce pasti memiliki manajemen pemasaran dan juga target yang berbeda-beda. Shopee dan tokopedia merupakan salah satu contoh e-commerce yang banyak digunakana oleh mahasiswa UIN STS Jambi, karna kemudahan serta banyak diskon yang terus diberikan ketika kita belanja, hal ini yang menyebabkan kenapa banyak mahasiswa lebih memilih belanja online daripada dating langsung ketempatnya. Persaingan yang ketat antara shopee dan tokopedia menyebabkan setiap perusahaan harus berkeja semaksimal mungkin untuk dapat bersaing dengan perusahaaan lain. Tokopedia sendiri berdiri pada tahun 2009 dan merupakan e-commerce buatan Indonesia, sedangkan shopee berdiri pada tahun 2015 buatan singapura. Pada tahun 2020 awal pandemic shopee menjadi e-commerce yang paling banyak dikunjungin mengalahkan tokopedia, kemudian pada tahun 2021 tokopedia kembali mengalahakan shopee, sehingga shopee menduduki e-commerce kedua setelah tokopedia. Data yang ditemukan pada tahun 2020 Shopee (93, 4 juta) kunjungan, Tokopedia (86,1 juta) kunjungan. Pada tahun 2021 tokopedia sebesar 32,04\% dan shopee 72,4\%. Dalam penenlitian ini penulis memberikan saran tanpa adanya manajemen pemasaran suatu perusahaan akan hancur, karna tidak adanya yang mengantur dalam hal cara mempromosikan, mengatur pemasaran dengan baik
\end{abstract}

Kata Kunci : Manajemen Pemasaran, Shopee, Tokopedia

\section{PENDAHULUAN}

Dizaman yang serba modern seperti sekarang ini tidak bisa kita pungkiri hidup tanpa sosial media, di zaman yang semakin canggih setiap harinya memberikan kita kemudahan dalam mengakses segala sesuatu. Kebutuhan primer manusia yang berupa sandang, pangan, dan papan sekarang berkembang danada kebutuhan lain yang harus dipenuhi yaitu keinginan manusia. Ketika manusia mengingkan sesuatu dia dapat melakukan transaksi belanja atau dapat membuatnya sendiri. Berbelanja tidak dapat di pisahkan dengan kehidupan kita sehari-hari, jika dahulu belanja hanya dilakukann dengan cara bertatap muka ataupun datang langsung ketokohnya berbeda dengan zaman yang serba modern seperti sekarang, pola belanja masyarkat sekarang sudah canggih, banyaknya marketplace yang memberikan kemudahan dalam mengakses ataupun mencari barang yang ingin kita beli salah satunya yang membuat pola belanja masyarakat berubah. Berlanja online merupakan sistem belanja yang memudahkan pembeli untuk tidak datang langsung ketempatnya, melaikan hanya tinggal memesan saja dan menungguh beberapa waktu barang mereka sudah sampai dirumah mereka masing-masing, salah satu alasan mengapa masyarakat lebih memilih untuk belanja online saja, tidak begitu banyak menghabiskan tenaga mereka.

Karena hal ini juga yang menyebabkan Indonesia menjadi perdagangan online atau ecommerce terbesar di Asia Tenggara. Mengutip dari Business Insider, nilai transaksi eCommerce di Indonesia diperkirakan mencapai US\$ 130 juta atau setara dengan Rp 1,7 triliun (kurs: Rp 13.114 per dolar AS). Bahkan, hal ini membuat Indonesia menjadi pasar eCommerce ketiga terbesar di bawah China dan India. Karna percapaian ini membuat presiden 
Indonesia terpesona serta berapresiasi besar terhadap pertumbuhan e-commerce di Indonesia. pemerintah juga mengapresiasi menculnya e-commerce baru seperti marketplace.

Marketplace sendiri merupakan perantara antara penjual dan pembeli dalam dunia maya atau dapat dikatakan sebagai pihak ketiga, sedangkan e-commerce merupakan transaksi perdagangan online. Contoh-contoh marketplace yang ada di Indonesia, diantaranya; shopee, tokopedia, lazada, dan lain sebagainya. Marketplace awal mulanya muncul di Amerika pada tahun 1995 dengan adanya eBay dan amazon. Sedangkan di Indonesia sendiri pada tahun 1999 mulailah awal mulanya toko online yang didirikan oleh forum jual kasus, seiring berkembanganya terknologi digital dan internet di Indonesia, pada tahun 2009 tokopedia menjadi toko pertama yang berdiri dan berkembang sangat pesat, dan disusul dengan perusahan-perusahan lainya yang dapat membaca peluang yang besar kedepannya.

Tokopedia resmi diluncurkan pada tanggal 17 Agustus 2009, di bawah naungan PT Tokopedia yang didirikan oleh William Tanuwijaya dan Leontinus Alpha Edison pada 6 Februari 2009. Sejak resmi diluncurkan, PT Tokopedia berhasil menjadi salah satu perusahaan internet Indonesia dengan pertumbuhan yang sangat pesat. ${ }^{1}$ Pada tahun 2014 tokopedia memecahkan rekor sebagai marketplace dengan investasi terbesar saat itu yakni senilai USD 100 juta. Tokopedia telah berkembanga menjadi sebuah unicorn yang berpengaruh tidak hanya di Indonesia tetapi juga di Asia Tenggara. ${ }^{2}$ Tokopedia juga turut mendukung para pelaku usaha mikro kecil dan menengah (UMKM), tokopedia sudah berdiri selama 11 tahun, Selama itu pula banyak prestansi-prestasi yang tokopedia dapatkan dan juga banyak meluncurkan ide-ide baru utuk mengembangkan kemajuan tokopedia. Tokopedia merupakan marketplace terbesar yang ada di Indonesia.

External Communications Senior Lead Tokopedia, Ekhel Chandra Wijaya mengatakan pada September 2020 jumlah pengguna aktif bulanan Tokopedia tercatat lebih dari 100 juta pengguna, meningkat sekitar 10 juta pengguna dibandingkan dengan Januari 2020 atau sebelum pandemi. Tidak hanya itu, penjual yang terdapat pada tokopedia meningkat dari sekitar 7,2 juta pada bulan januari, menjadi 9,4 juta penjual pada September 2020. Chandra mengatakan “ tokopedia akan terus mengedepankan 5 hal guna mendorong perkembangan bisnis yaitu, pertama, memperkuat fondasi. Kedua, fokus ada kebutuhan konsumen. Ketiga, memperluas pemanfaatan data. Keempat, penggunaan teknologi kecerdasan buatan. Kelima, menjalankan kerangka kerja yang optimal secara finansial.

Sedangkan shopee adalah marketplace yang bisa dikatakan baru saja lahir, yaitu sekitar tahun 2015. Shopee merupakan situs elektronik komersial yang berkantor di Singapura di bawah naungan SEA Group (sebelumnya dikenal dengan nama Gerena), yang didirikan pada 2009 oleh forrest li.Pada tahun 2015 shopee pertama kali diluncurkan di Singapura, muncul pertama kali sebagai marketplace consumer to consumer $(\mathrm{C} 2 \mathrm{C})$. namun kini telah berubah menjadai model hibrid $\mathrm{C} 2 \mathrm{C}$ dan business to consumer (B2C). Sejak pertama kali diluncurkan pada tahun 2015 sejak itu meluas ke Malaysia, Thailand, Taiwan, Indonesia, Vietnam, dan Filipina. ${ }^{3}$ Pada tahun 2019 shopee sendiri sudah aktif di negra Brasil, menjadi negara pertama di Amerika Selatan dan luar Asia yang dikunjungi Shopee. ${ }^{4}$ Shopee sendiri hadir di Indonesia pada bulan Desember 2015, shopee berhaasil mempromosikan dalam waktu yang

\footnotetext{
${ }^{1}$ http://id.techinasia.com/toko-online-tokopedia-kirim-dua-juta-barang-per-blan/

2 "Jalan Panjang Tokopedia Menjadi Unicorn Indonesia". SWA.co.id (dalam bahasa Inggris). 2018-03-08. Diakses tanggal 2021-05-06

${ }^{3}$ Transaksi Shopee di Indonesia Terbesar di ASEAN | SWA.co.id". SWA.co.id (dalam bahasa Inggris). 2015-12-02. Diakses tanggal 2021-05-21.

${ }^{4}$ Tech in Asia - Connecting Asia's startup ecosystem". www.techinasia.com (dalam bahasa Inggris). Diakses tanggal 2021-05-21
} 
singkat. Pada tahun 2017, platform ini mencatat 80 juta unduhan aplikasi dengan lebih dari empat juta penjual dan lebih dari 180 juta produk aktif. Pada kuartal keempat tahun 2017, Shopee melaporkan nilai perdagangan bruto (GMV) sebesar US\$1,6 miliar, naik 206 persen dari tahun sebelumnya. ${ }^{5}$ Di kalangan konsumsi Indonesia,survei yang telah dilakukan pada bulan Desember 2017 oleh TheAsianParent mengungkapkan bahwa Shopee adalah platform belanja pilihan pertama bagi para ibu di Indonesia (73\%), diikuti oleh Tokopedia (54\%), Lazada (51\%), dan Instagram (50\%). ${ }^{6}$ Dari survey yang dilakukan kita bisa melihat bahwa masyarakat Indonesia pada tahun 2017 adalah pilihan untuk belanja oleh ibu-ibu. Persaingan marketplace di Indonesia cukup berat, tetapi shopee dapat masuk kedalam posisi 5 besar di Indonesia. Walaupun dapat dikatakan shopee baru saja diluncurkan tetapi shopee dapat bersaing dengan marketplace lainya, hal ini dapat dibuktikan dengan banyaknya penghargaan-penghargaan yang diberikan kepada shopee, salah satu contohnya penghargaan sebagai " the Indonesia netixen brand choive award 2017” sebagai katagori belanja online pada maret 2017.

Disetiap marketplace pasti memiliki manajemen tersendiri untuk dapat memajukan perusahaanya, apalagi manajemen pemasaran atau marketing management merupakan jenis manajemen yang sangat dibutuhkan dalam bisnis, dikarnakan inilah yang menentukan produk atau jasa kita dikenal oleh konsumen, maka dari itu setiap perusahaan harus benar-benar memperhatikan dalam marketing management ini agar tidak terjadinya kegagalan. Manajemen pemasaran sendiri bertujuan untuk mengenalakan produk kita agar dikenal oleh halayak orang, sehingga orang mau membeli barang kita.manajemen pemasaran ini berfokus pada bagaimana kita mempromosikan ataupun memgenalkan produk kita keberbagai masyakat. Begitu juga seperti tokopedia dan shopee pasti memiliki manajemen pemasaran yang berbeda-beda agar dapat menarik minat pembeli untuk membeli barangnya. Contohnya seperti tokopedia yang memiliki pemasaran dalam mempromosikan barangnya, yang pertema dengan mengikuti trend social media, seperti yang kita ketahui tokopedia merupakan belanja online hal ini tentu mereka harus pintar-pintar dalam mengikuti trand, jika mereka tidak mengikuti trand yang ada mereka akan membuat para konsumen itu beralih ketokoh lainnya, dikarnakan bosen dengan tampilan yang tidak berubah-rubah dikarnekan ketinggalan trend. Kedua dengan memberika loyalty gift untuk konsumen, seperti memberikan giveaway dancashback yang berguna untuk membuat konsumen puas dengan layanan maupun produk yang ada di tokopedia. menggunakan brand ambassador, seperti yang kita ketahui tokopedia banyak sekali mencari bintang-bintang ternama yang dapat menarik konsumen, seperti padatahun 2021 tokopedia mengundang dua bintang gelombang yaitu, blackpink dan BTS. Keempat memberikan ampresia dan yang terakhir mengikuti event-event.

Tidak hanya tokopedia shoope juga memiliki manajemen pemasaran yang cukup dapat menarik perhatian konsumen. Yang pertamamemakai strategi tren yang ada, trend mememang hal yang penting yang harus kita ikuti agar kita tidak ketinggalan jalan dan juga tidak membuat konsumen bosan. Kedua memperbanyak promosi kepada pelanggan, promosi merupakan hal yang penting dalam suatu bisnis agar lebih luas lagi produk kita dikenal oleh masyarakat. Ketiga jaminan harga termurah harga merupakan hal yang penting juga ketika kita ingin membeli sesuatu apalagi dikondisi yang bisa dibilang sedang tidak emmiliki uang, shopee menyediakan harga yang terjangkau lebih murah. Keempat menggunakan brand ambassador sama seperti tokopedia dan juga toko lainnya pasti menggunakan bran ambassador, karna jika kita memanggil orang-orang yang sudah terkenal konsumen menarik perhatian konsumen. Kelima mengikuti event, event- event sepeti hari beli online nasional, shopee memberikan

\footnotetext{
${ }^{5}$ https://www.nst.com.my/business/2017/11/306106/shopee-records-80-mil-downloads-over-2-years

${ }^{6}$ Tay, Vivienne. "Shopee found to be the most popular e-commerce site for Indonesian mothers". Marketing 
promo sebanayak-banyaknya. Keenam mengunkana media yang tepat. Itu lah beberapa manajemen pemasaran yang digunakan oleh tokopedia dan juga shope dalam mempromosikan usahanya.

\section{METODE PENELITIAN}

Metode yang digunakan dalam penelitian ini adalah deskriptif kualitatif. Penelitian kualitatif mencakup subjek yang dikaji dan kumpulan berbagai data empiris, studi kasus, pengalaman pribadi, introspeksi, perjalanan hidup, wawancara, teks-teks hasil pengamatan, historis, interaksional, dan visual yang menggambarkan saat-saat penelitian dan makna keseharian serta problematika dalam kehidupan seseorang (Putra, 2013: 62).

Pengumpulan data ini menggunakan riset serta wawancara, dan juga menggunakan kumpulan berbagai data-data yang diambil dari sumber-sumber website. Narasumber dari penelitian ini khususnya adalah mahasiswa/i UIN STS Jambi yang berjumlah sekitar 30 mahasiswa/idari fakultas ekonomi dan bisnis islam angkatan 2020.

Subjek yang ada dalam penelitian ini adalah perusahaan shopee dan tokopedia yang merupakan e-commece yang sangat berpengaruh di Indonesia, dimana dua perusahaan ini memiliki persaingan yang sangat ketat dalam mempromosikan perusahaannya. Data yang penulis dapatkan pada tahun 2020 shopee menjadi e-commece yang banyak dikunjungin yang dapat dikatakan mengalahkan tokopedia, sedangkan tokopedia pada awal tahun 2021 merebut tempat shopee sehingga shopee mejadi e-commece kedua di Indonesia yang banyak di kunjungin. Objek dalam penelitian ini adalah Persaingan antara dua perusahaan tersebut. Data yang telah dikumpulkan kemudian dibandingkan setiap penggunaan manajemen pemasaran setiap perusahaan dan amna perusahaan yang banyak digemari/dikunjungin oleh orang-orang.

\section{HASIL DAN PEMBAHASAN}

Hasil yang ditemukan dari sumber wawancara serta riset yang dilakukan pada mahasiswa UIN STS Jambi khususnya pada prodi ekonomi syariah angkatan 2020, ditemukan banyak mahasiswa laki-laki lebih menyukai tokopedia sedangkan mahasiswa perempuan lebih tertarik pada shopee. Sekitar 30 mahasiswa yang terdiri dari mahasiswa laki-laki 12 orang dan 18 mahasiswa perempuan. Dari hasil penelitian angket didapatkan hasil yang menyukai tokopedia sebanyak 10 orang dan yang menyukai shopee sebanyak 18 orang, sisanya menyukai keduanya. Mahasiswa perempuan lebih menyukai shopee, hal ini dikarnakan dishopee memang banyak menjual mengenai kecantikan, fashion, dan barang-barang lucu yang tengah hype. Sedangkan mahasiswa laki-laki lebih tertarik kepada tokopedia karna memiliki tampilan harga yang jelas dan jujur contohnya jika dijualnya gopro akan ditampilkannya gopro dengan monopod, tidak monopodnya saja.Sedangkan dishopee biasanya bervarian mulai dari harganya, missal harganya murah itu hanya dapat gopronya saja tidak dengan monopod. Contoh lain seperti membeli sparepart mobil, motor, sepeda dan lainya, dapat dikatakan bahwa laki-laki tidak menyukai hal yang bertele-tele dalam mencari barang yang dia inginkan.

Tetapi jika anda ingin memasukan produk ada yang sasarannya adalah prempuan maka shopee tempat yang tepat, dan jika sasaran pasar adalah laki-laki, tokopedia jauh lebih tepat. Dari penelitian dengan menggunakan metode deskriptif kualitatif setiap perusahaan pasti memiliki daya tarik tersendiri, seperti shopee yang memberikan jaminan harga yang lebih murah dari pada tokopedia. Hal ini yang menyebabkan kenapa banyak mahasiwa/i lebih memilih shopee karna harga yang pas dikantong. Dapat disimpulkan bahwa shopee dapat 
dikatakna sebagai aplikasi yang lebih cenderun menawarkan barang perempuan atu lebih feminimitas dan laki-laki aplikasi maskulinitas. sebenarnya setiap perusahaan pasti memiliki target sasaran pemasaran produk yang berbeda-beda.

Manajemen pemasaran pada suatu perusahaan merupakan hal sangat penting, dimana manajemen pemasaran ini fokus pada sampai mana suatu produk ataupun usaha kita dapat dikenal dikalangan masyarakat. Setelah kita berhasil mendapatkan konsumen yang tertarik kepada produk atau usaha kita harus mencari cara bagaimana konsumen itu bertahan untuk terus menggunakan produk. Bagian instrument pemasaran yang tajam adalah pesan (massage) yang dikomunikasikan kepada calon pembeli melalui berbagai unsur yang terdapat dalam program promosi. Hal ini juga yang dilakukan oleh shopee dan tokopedia yang terus berlombalomba dalam mencari konsumen sebanyak-banyaknya dan bersaing sehat dalam mempromosikan usahanya.seperti khasus pada tahun 2020 shopee menjadi e-commerce yang paling banyak dikunjungin di Indoensia dengan kunjungan sebanyak Shopee (93, 4 juta), Tokopedia (86,1 juta), Bukalapak (35,2 juta), Lazada (22 juta), dan Blibli (18,3 juta). ${ }^{7}$ Persaingan yang semakin ketetap antara shopee dan tokopedia pada tahun 2021 tokopedia mampu menggeser posisi shopee. Berdasarkan data SimilarWeb kategori Marketplace di Indonesia selama periode Januari 2021, Tokopedia memimpin dengan traffic share sebesar $32,04 \%$. Jumlah kunjungan bulanan ke layanan e-commerce tersebut sebanyak 129,1 juta. Porsi kunjungan melalui mobile mendominasi sebesar 62,7\%, sedangkan dari desktop 37,3 persen. Rata-rata durasi kunjungan 6 menit 37 detik. Sedangkan shopee dengan traffic share sebesar 29,78 persen. Jumlah kunjungan bulanan sebanyak 120 juta. Shopee paling banyak diakses melalui mobile 72,4\% dan desktop 21,3\%. Rata-rata durasi kunjungan 6 menit 30 detik. Kemudian disusul dengan bukalapak, lazada.

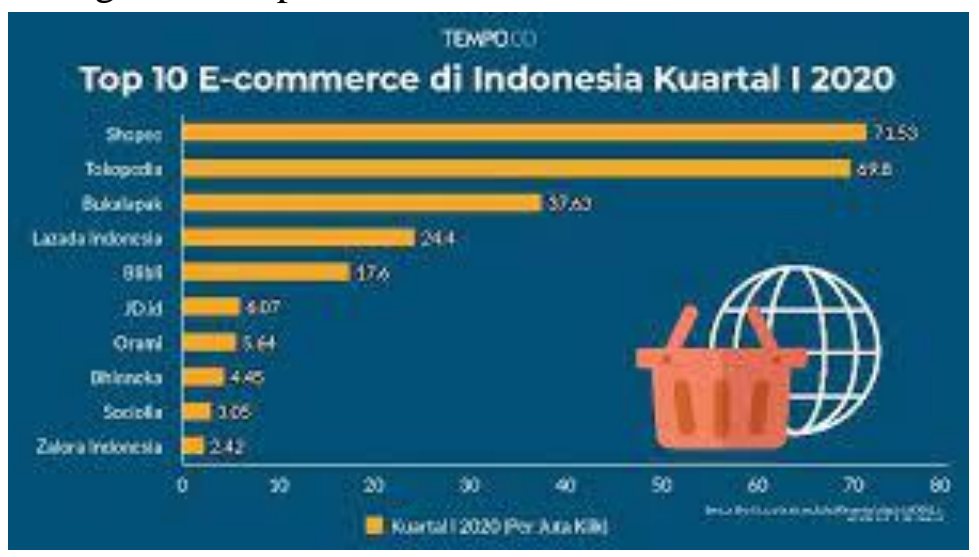

Sumber: TEMPOCO

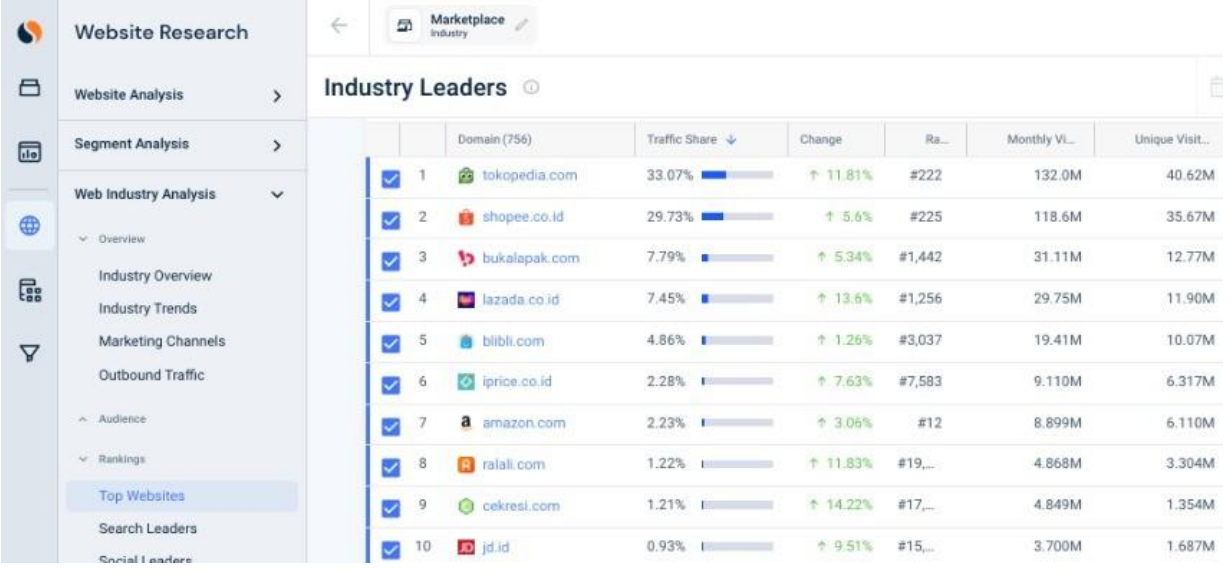


Sumber: marketing communication,by Dwi wulandari

Dari gambar serta penjelasan diatas dapat kita ambil kesimpulan dari pembahasan penelitian ini. Dimana suatu pemasaran merupakan hal yang penting agar dapat membuat usaha kita dikenal oleh masyakat luas. Bukan hanya dalam mempromosikan usaha saja tetapi juga bagaimana membuat konsumen mau mempromosikan usaha kita tanpa kita suruh. Contohnya pada tokopedia yang memberikan layanan Rp. 0 untuk pengguna baru, dan shopee dengan memberi barang yang murah serta kualitas yang bagus, jika konsumen sudah tertarik dengan usaha yang dicoba otomatis dia akan mudah mengajak konsumen lain untuk ikut terjun dalam melihat produk tersebut.Perbedaan penggunaan setiap manajemen pemasaran dalam usaha pasti berbeda-beda. Yang terpenting dalam suatu usaha harus ada yang mengatur tentang pemasaran suatu produk, kelebihan dan kekurangan dalam setiap usaha menjadikannya sebuah perbedaan yang mendasar. Dari nasumber yang didapat yaitu mahasiswa UIN STST Jambi yang berjumlah sekitar 20 mahasiswa pada jurusan ekonomi syariah, dapat disimpulkan mereka lebih tertarik pada akun shopee dikarnakan akuns shope memberikan diskon, harga yang murah dan juga geratis ongkir yang terus diberikan setiap bulannya, dan tampilan yang lebih menarik perhatian mata.

Tokopedia merupakan usaha buatan Indonesia yang sedang gencar memperkenalkan produk buatan Indonesia, yang mengajak seluruh masyarakat Indonesia bangga memiliki ataupun menggunakan produk buatan asli Indonesia. Hal ini mungkin ynag membuat tkokpedia pada tahun 2021 menjadi e-commerceyang banyak dikunjungin. Selain di Indonesia shopee yang berkembang diberbagia negara misalnya dinegara asalnya shopee menjadi $e$ commerceyang terbesar. "Shopee paling juara di aplikasinya kerena di download paling banyak oleh user untuk aplikasi mobile apps. Sementara, tokopedia lebih kuat di website" jelas Ai Mulyani.

\section{KESIMPULAN}

Dari pemaparan serta pembahasan diatas dapat kita simpulkan:

1. Shopee merupakan e-commerce yang berasal dari negara singapura, yang diluncurkan pada tahun 2015 dan mengalami peningkatan yang cukup cepat. Tokopedia sendiri merupakan buatan negara Indonesia yang diluncurkan pada tahun 2009 dan memiliki banyak sekali prestasi.

2. Tokopedia memiliki ciri khas berwarna hijau dan terdapat tas belanja yang memiliki karakter. Sedangkan shopee berwarna orange dengan lambing tas berwarna putih da nada huruf S. lambing ini sendiri sering berubah-ubah karna adanya pembaruan agar lebih menarik perhatian konsumen.

3. Tokopedia menyajikan diskon, geratis ongkir dan juga sistem COD. Sama dengan tokopedia shopee juga memeberikan diskon, geratis onkir setiap bulannya, sistem COD, harga terjangkau murah. Kedua aplikasi ini juga memilliki game yang dapat dimainkan sehingga dapat menambah point bertambah dan bisa ditukarkan.

4. Setiap e-commerce pasti memiliki cara tersendiri untuk menarik perhatian konsumen, persaingana dalam suatu bisnis suah sangat biasa dikalngan pembisnis. Setiap perusahaan pasti akan memberikan segala hal dengan sebaik-baiknya.

\section{SARAN}


Analisis manajemen pemasaran dalamsuatu usaha sangat penting. Dikarnakan tempa adanya suatu manajemen dalam suatu hal pasti akan sangat berdampak buruk bagi usahanya. Apalagi suatu pemasaran bagaimana cara mempromosikan barang hingga sampai kekonsumen dengan baik. Jika dalam suatu perusahaan tidak adanya manajemen pemasaran, tunggu saja saat kehancuran bagi perusahaan tersebut karna tidak adanya target tidak adanya tujuan yang benarbenar ingin dicapai. Manjemen pemasaran yang baik akan menghasilkan sesuatu yang baik juga untuk kemajauan perusahaan. Setiap perusahaan memiliki manajemen pemasaran dengan cara yang berbeda-beda, dan juga target pasar yang berbeda. Setiap perusahaan pasti memiliki keunggalan tersendiri dalam bidangnya.

\section{DAFTAR PUSTAKA}

Handisetyadi. Tokopedia dan shopee, manakah yang lebih baik sebagai pelaku bisnis?. Artikel https://www.magoostoreid.com/post/tokopedia-vs-shopee-mana-lebihbaik-sebagai-pelaku-bisnis-online (diakses pada 20 Mei 2021).

Kamaruddin. 1990. Manajemen Berdasarkan Sasaran. Jakarta: Bumi Aksara.

Rachel. Strategi manajemen shopee dalam menarik perhatian pelanggan. https://yoursay.suara.com/news/2019/12/10/131146/strategi-shopee-dalammenarik-perhatian-pelanggan?page=all (diakses pada 24 April 2021).

Sirlclo. Sejarah perkembangan marketplace di Indonesia. https://www.sirclo.com/sejarahperkembangan-marketplace-di-indonesia (diakses pada 01 Mei 2021).

Wikipedia. Tokopedia.Artikel. https://id.wikipedia.org/wiki/Tokopedia\#cite_note-6(diakses pada 15 April 2021). 